\title{
Improving the Physico-Mechanical Properties of Eco-friendly Composite Made From Bamboo
}

\author{
Ragil Widyorini ${ }^{1}{ }^{1, a}$, Ari Puspa Yudha ${ }^{1}$, Ramadhanu Isnan ${ }^{1}$, Ali Awaluddin², \\ Tibertius Agus Prayitno ${ }^{1}$, Agus Ngadianto ${ }^{3}$, and Kenji Umemura ${ }^{4}$ \\ ${ }^{1}$ Faculty of Forestry, Universitas Gadjah Mada, \\ Jl.Agro no. 1, Bulaksumur, Yogyakarta, 55281 Indonesia \\ ${ }^{2}$ Faculty of Engineering, Universitas Gadjah Mada, Yogyakarta, Indonesia \\ ${ }^{3}$ Vocational School, Universitas Gadjah Mada, Yogyakarta, Indonesia \\ ${ }^{4}$ Laboratory of Sustainable Materials, RISH, Kyoto University, Kyoto, Japan \\ arwidyorini@gmail.com
}

Keywords: binderless board, bamboo, citric acid, natural binder, physico-mechanical properties

\begin{abstract}
This research focused on physical and mechanical properties of biocomposite made from bamboo and citric acid as natural binder. Bamboo particles was mixed with citric acid at $0-40$ $\mathrm{wt} \%$ resin content based on air-dried particles and each mixture was hot pressed at $180{ }^{\circ} \mathrm{C}$ for 10 min. The result showed that addition of citric acid improved significantly the physical and mechanical properties of particleboards. The thickness swelling was $50 \%$ for bamboo binderless particleboard $(0 \mathrm{wt} \%)$, whereas it decreased to $7 \%$ under a resin content of $10 \mathrm{wt} \%$. The optimum resin content in this study was $30 \mathrm{wt} \%$, while the modulus of rupture dan the modulus of elasticity were $14 \mathrm{MPa}$ and $4.5 \mathrm{GPa}$, respectively. The ester linkages were detected by Fourier transform infrared spectroscopy, indicating that carboxyl groups from citric acid reacted with hydroxyl groups from bamboo to produce better properties of particleboard, especially its dimensional stability. Based on these results, it was concluded that citric acid could be as a potential natural binder for bamboo particleboard.
\end{abstract}

\section{Introduction}

Considering the environmental issues, many researches have been focusing on reduction of the synthetic adhesives in wood-based materials production. For example, binderless board is a product whose bonding depends mainly on the chemical composition of the raw materials without the use of adhesives. There are no resins or adhesives used in binderless boards production, therefore the performance of the boards is strongly affected by chemical characteristics of the raw materials. In addition, activated chemical components during treatment or pressing are an effective process to build self-bonding in producing binderless board. In our previous research, we were able to make bamboo particleboard without any synthetic resin adhesive using the hot pressing system [1]. However, the properties of the binderless board, such as the dimensional stability properties, still need to be improved. Further development to improve the properties of the boards, with a safe and environmentally friendly technique, is very important.

The possibility of citric acid as a natural adhesive for wood was investigated by fabricating acacia wood and bark moldings [2,3]. The results showed that addition of citric acid increased drastically the mechanical properties and water resistance of the wood and bark moldings. The same trends were also found in bamboo particleboard [4], which the physical and mechanical properties improved significantly by the addition of citric acid up to $20 \mathrm{wt} \%$. However, the optimum conditions have not been achieved yet on that study. Citric acid which is a natural organic polycarboxylic acid, is supposed to act as natural binder for board [2]. Ester linkages have been detected by fourier transform infrared spectroscopy (FTIR), which indicated that the citric acid could react with the wood [5] and producing the good adhesion [3]. Clear bonding mechanism is still unknown until now, however it is believed that ester linkages between carboxyl groups from citric acid and hydroxyl groups from wood supports the adhesion between both materials. 
The researches on application citric acid as natural binders are still limited, especially for nonwood materials. This paper was designed to investigate the characteristic of bamboo particleboard which bonded using citric acid with different resin content. Binderless board from bamboo particles were also produced with the same pressing condition, as a reference. Considering that chemical characteristic of bamboo is different with wood, FTIR analysis is also conducted.

\section{Experimental Procedures}

Petung bamboo particles which passed through aperture sizes of 10 mesh were used as materials in this research. The particles were then air-dried to a moisture content of around $12 \%$. Citric acid (anhydrous) was used without further purification. Citric acid was dissolved in water with the concentration of the solution was adjusted to $60 \mathrm{wt} \%$. The solution was used as adhesive and sprayed onto particles at $10-40 \mathrm{wt} \%$ resin content based on the weight of the air-dried particles. The sprayed particles were then dried in oven over night at $80^{\circ} \mathrm{C}$ to reduce the moisture content.

The particles were hand-formed into a mat by using forming box, followed by hot pressing at $180^{\circ} \mathrm{C}$ for $10 \mathrm{~min}$ into particleboard. Binderless particleboards from bamboo were also produced in the same condition. The dimension of the particleboard was $250 \times 250 \times 7 \mathrm{~mm}$, with the target board density was set at $0.9 \mathrm{~g} / \mathrm{cm}^{3}$. Three replications were manufactured for each resin content in this research. Prior to the evaluation of the mechanical and physical properties, the boards were then conditioned at ambient conditions for about 10 days.

The properties of the particleboards were evaluated basically according to the Japanese Industrial Standard for Particleboards A 5908 [6]. Tests were carried out for modulus of rupture (MOR), modulus of elasticity (MOE), internal bond (IB) strength, and thickness swelling (TS) as well as water absorption (WA) after water immersion for $24 \mathrm{~h}$. Fourier Transform Infrared (FTIR) measurement of the particleboards was also performed. All infrared spectras were obtained with FTIR spectrophotometer using $\mathrm{KBr}$ disk method and were recorded by means of an average of 10 scans at a resolution of $16 \mathrm{~cm}^{-1}$.

\section{Results and Discussions}

All of the bamboo composite boards could be produced without any delamination. Fig. 1 shows the effect of resin content on physical properties of bamboo particleboards. It is obvious from Fig. 1 that the addition of citric acid causes an improvement in dimensional stability of the boards. The TS value was $50 \%$ for bamboo binderless particleboard $(0 \mathrm{wt} \%)$, whereas it decreased drastically to 7 $\%$ under a resin content of $10 \mathrm{wt} \%$ and then kept an almost constant value. All of the TS values of the citric acid-bonded particleboards could meet the maximum requirement of JIS A 5908 (12\%). A similar trend was observed for the WA values (Fig. 1). The WA of binderless board $(0 \mathrm{wt} \%) \mathrm{was}$ around $135 \%$ and decreased to $34 \%$ and $18 \%$ with increasing resin content to $10 \mathrm{wt} \%$ and $40 \mathrm{wt} \%$, respectively. It clarified that bamboo particleboards bonded with citric acid had excellent water resistance. The same result was also found on acacia wood and bark-molding product bonded with citric acid [2,3].

Fig. 2 shows relationship between MOR and MOE of bambo particleboards with resin content. It showed that bamboo binderless particleboards $(0 \mathrm{wt} \%)$ had almost no bending properties. However, the MOR and MOE values increased significantly after addition of the citric acid. All of the boards bonded using citric acid had MOR and MOE that exceed the minimum requirements for grade 8 type JIS A 5908 particleboards, i.e. $8 \mathrm{MPa}$ and $2 \mathrm{GPa}$. The bending properties increased gradually as the resin content increased. The optimum MOR and MOE values were $14 \mathrm{MPa}$ and 4.5 GPA with a $30 \mathrm{wt} \%$ citric acid content, which met grade 13 type. It showed that bamboo particleboards bonded using citric acid had high performance on mechanical properties and good dimensional stability, as also found on citric acid-bonded acacia wood and bark-molding product $[2,3]$. 


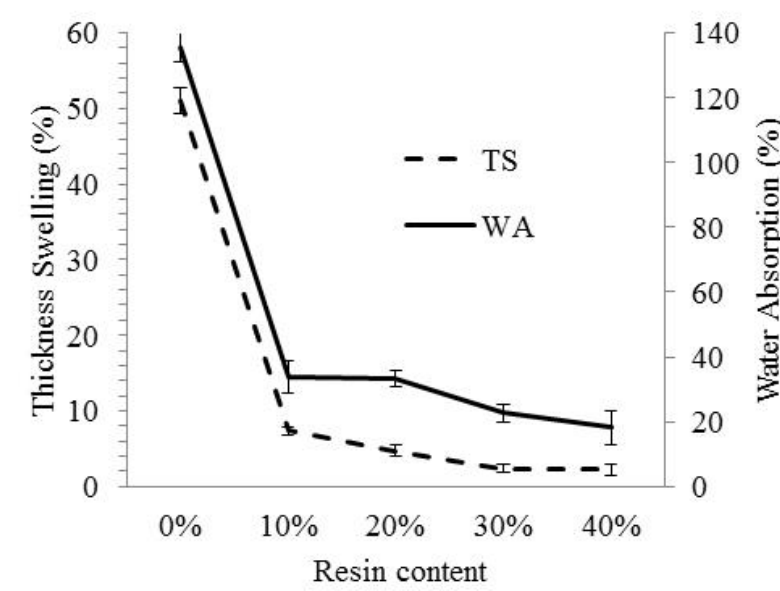

Fig 1. Effect of resin content on physical properties of particleboard

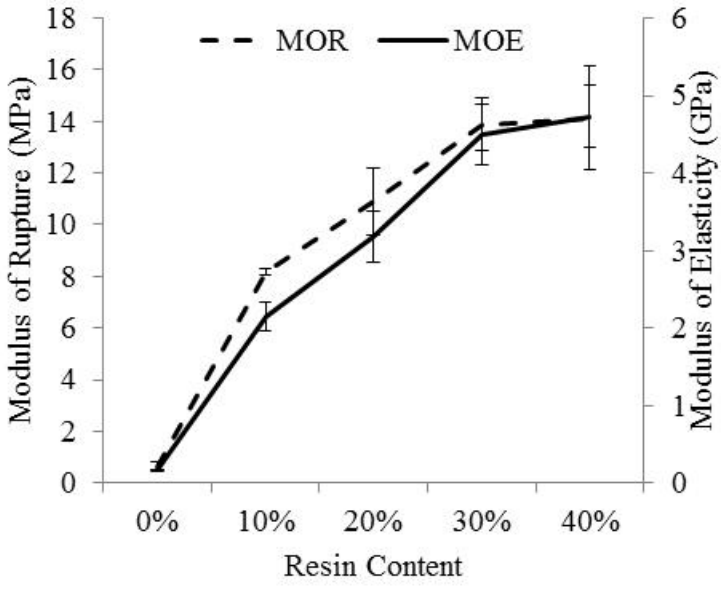

Fig 2. Effect of resin content on bending properties of particleboard

The board densities were range in $0.74-0.75 \mathrm{~g} / \mathrm{cm}^{3}$ for binderless particleboard, while increased to $0.84-0.87 \mathrm{~g} / \mathrm{cm}^{3}$ for citric acid-bonded boards. Specific MOR, MOE and IB values were then calculated to exclude the effect of the density (Fig. 3 and 4). It showed that the trend of actual and specific MOR values were not different, as well as trend for MOE values. After added only $10 \mathrm{wt} \%$ citric acid content, the bending strength of the boards were improved almost 10 times compared to the bending strength of binderless board. It clearly confirmed that citric acid could be act as good binding agent.
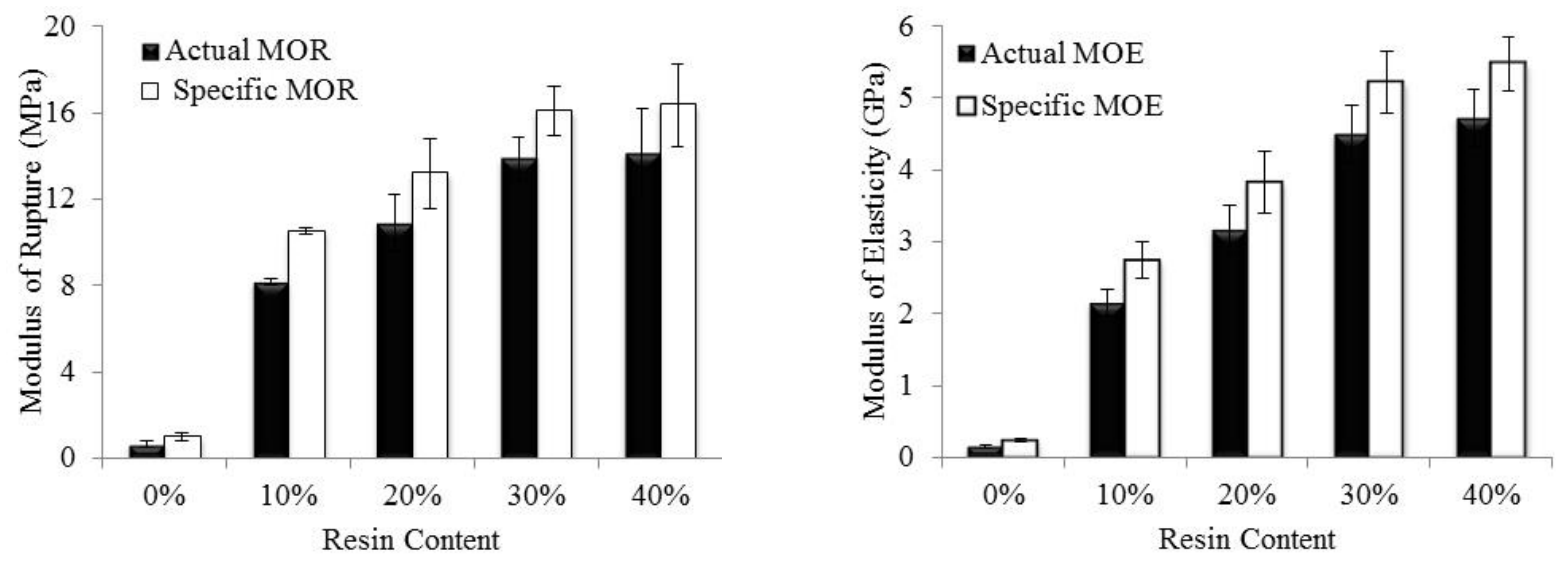

Fig 3. Actual and spesific MOR and MOE of bamboo particleboards

Figure 4 shows relationship between IB strength of bambo particleboards and resin content. The IB value of binderless board was $0.02 \mathrm{MPa}$ and improved significantly after addition of citric acid. The IB value of board with $10 \mathrm{wt} \%$ resin content was $0.2 \mathrm{MPa}$, which was almost 10 times than that of binderless board. All of the boards bonded with citric acid had IB strength that exceed the minimum requirements for grade 8 type JIS A 5908 particleboards, i.e. $0.15 \mathrm{MPa}$. In this research, the maximum IB value of board with $40 \mathrm{wt} \%$ resin content was $0.29 \mathrm{MPa}$, while the specific IB considering the density was $0.32 \mathrm{MPa}$.

Figure 5 shows the infrared spectra of bamboo particleboard at different resin content. The absoption band at $1734 \mathrm{~cm}^{-1}$ was ascribed to $\mathrm{C}=\mathrm{O}$ stretching derived of carbonyl groups [2,3,7]. It clearly showed that the presence of ester groups was higher with increasing resin content. The result confirmed previous studies [2,3] that the bonding mechanism was ester linkages between carboxyl groups from citric acid with hydroxyl groups from bamboo. 


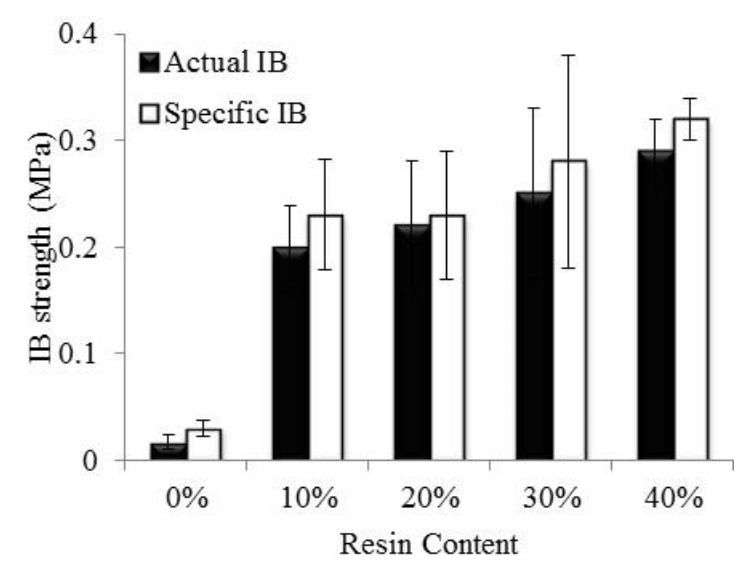

Fig 4. Effect of resin content on actual and specific IB strength

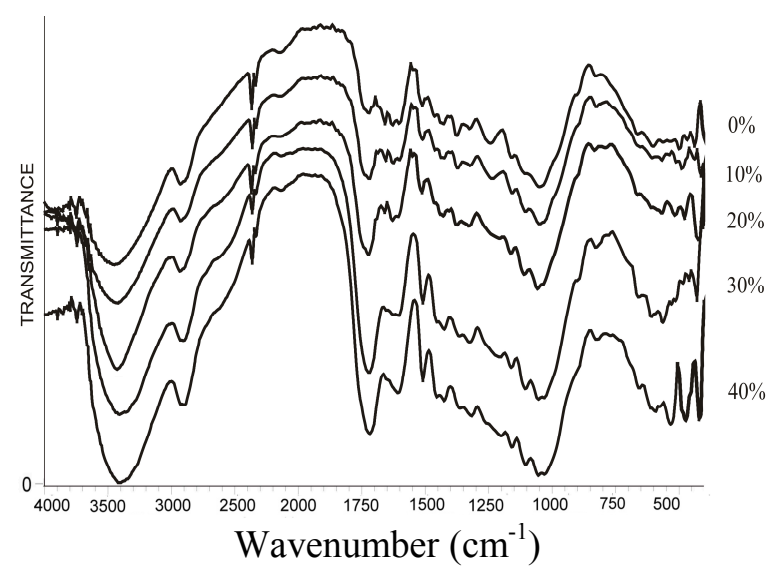

Fig 5. FTIR spectra of bamboo particleboard at different resin content

\section{Conclusions}

The results showed that bamboo composite bonded with citric acid had excellent water resistance and better mechanical properties compared to binderless board. Compared to the binderless boards, the IB value of citric acid-bonded boards with $10 \mathrm{wt} \%$ resin content increased almost 10 times. The optimum resin content in this study was $30 \mathrm{wt} \%$, which the MOR dan MOE of particleboards were $14 \mathrm{MPa}$ and $4.5 \mathrm{GPa}$, respectively. Fourier transform infrared analysis showed that the presence of ester groups was higher with increasing resin content. The result indicated that carboxyl groups from citric acid were ester linked with hydroxyl groups from bamboo producing better properties of particleboard, especially its dimensional stability. Based on this result, it was concluded that citric acid could be as good binding agent for bamboo particleboard.

\section{Acknowledgements}

This work was financially supported by Multidisciplinary Research Grant Universitas Gadjah Mada (LPPM-UGM/1379/LIT/2013), Directorate General of Higher Education, Ministry of National Education, Indonesia.

\section{References}

[1] R. Widyorini, A.P. Yudha, and T.A. Prayitno, Some of the properties of binderless particleboard manufactured from bamboo, Wood Research Journal, 2 (2011) 89 - 93.

[2] K. Umemura, T. Ueda, S.S. Munawar, and S. Kawai, Application of citric acid as natural adhesive for wood, Journal of Applied Polymer Science, 123 (2012) 1991 - 1996.

[3] K. Umemura K., T. Ueda, and S. Kawai, Characterization of wood-based molding bonded with citric acid, Journal of Wood Science, 58 (2012) 38 - 45.

[4] R. Widyorini, A.P. Yudha, A. Damarraya, K. Umemura and S. Kawai, Characteristic of bamboo particleboard bonded using citric acid, Wood Research Journal (accepted in 2013).

[5] S.B. Vukusic, D. Katovic, C. Schramm, J. Trajkovic, and B. Sefc, Polycarboxylic acids as nonformaldehyde anti swelling agents for wood, Holzforschung 60, (2006) 439 - 444.

[6] Japanese Industrial Standard for Particleboard A 5908 (2003).

[7] N. Reddy and Y. Yang, Citric acid cross-linking of starch films, Food Chemistry, 118 (2010) $702-711$. 